\title{
DIVING PROTECTION AGAINST NUCLEAR CONTAMINANTS
}

\author{
Nicușor CHIRIPUCI \\ Diving Center, Constanţa, Romania \\ nicusor.chiripuci@navy.ro \\ Emil AVRAM \\ Diving Center, Constanţa, Romania \\ emil.avram@navy.ro \\ Laurențiu MOCANU \\ Diving Center, Constanţa, Romania \\ laurentiu.mocanu@navy.ro
}

\begin{abstract}
The risks of radioactive water contamination are high today and divers can make a decisive contribution to removing these risks. The equipment used and the diving procedures are specific. The specialists of the Research Laboratory, in collaboration with those of the Hyperbaric Laboratory of the Diving Center from Constanta, have contributed to the development of this equipment and the diving procedures in the radioactive contaminated environment.
\end{abstract}

KEYWORDS: diving, dosimeter, equipment, nuclear

\section{Introduction}

In today's world a new challenge has emerged, which cannot be seen, touched, tasted or smelled, this is nuclear radiation.

Nuclear reactors are enclosed in steel reinforced concrete structures. During the operating period, the reactor pipes are partially filled with approximately $200 \mathrm{~m}^{3}$ of circulating water to cool this environment. The danger of contamination is real.

The divers can respond to an emergency where the diving location is contaminated with a radiation source or may be required to perform an inspection, repair or maintenance in the nuclear reactor's fuel tanks. For this reason they are trained for diving near a radiation source.
Diving in the nuclear environment requires additional protection from diving into chemically, hydrocarbon or biologically contaminated waters.

Because of this, specific precautions are required, the equipment is made of a material that will not absorb radiation and which after each dive will have to be checked.

To ensure that the diver does not receive a dangerous dose of radiation during the dive, he must have a mini dosimeter or other similar device, which can provide the information needed to limit the total dive time and be informed where the radioactive location is (Stanciu, 2011). 


\section{Diving at the Nuclear Plants}

For a diver who works in such an environment, a whole series procedures must be performed: a psychological evaluation, an action plan and many hours of preparation. The training course is an operative one, in action, in case of loss of protection, of limitation of space, of exclusion for the dangerous material and of course, of knowing the work in the radioactive environment. Once this course is completed, the diver can enter the territory of the nuclear plant. To enter he must pass through a bomb detector, a metal detector and after that he will be handed a recognition card. After passing through the guard room, the diver can begin divings (Naval Sea Systems Command USA, 2008).

Depending on the location of the dive operation, several meetings will be set up with specialist engineers to establish the radiation protection. The diving team must know the location, the temperature and the depth of the water, the potential sources of radiation and their doses. These meetings can continue several hours for a full understanding of the phenomenon.

For a water temperature exceeding $35{ }^{\circ} \mathrm{C}$, which usualy happens in the cooling basins of the nuclear power plants, the diver can get tired very quickly, triggering the risk of thermal stress. If in the diving location this temperature level is usually exceeded there must be considered several options. Thus, the equipment for reducing the temperature of the divers can be used or the diving may be delayed until the temperature is reduced. Usually it's used the first option, in order to not increase the intervention time. There are two possibilities to reduce the temperature inside the divers suits in such situations:

- Ice jacket for short dives, until the ice melts.

- Suits with cooling water, more suitable because they keep a low temperature throughout the dive.
Cooling suits, similar to hot water heating suits, have been designed by specialist engineers, for their durations longer than 1 hour and for water temperatures higher than $49{ }^{\circ} \mathrm{C}$. They are made of a light weight material, with very small diameter tubes, through which the cooling water flows. The water is drained outside the suit through a small container, mixed with ice wich is then sent by means of a pump, through the suit, to maintain a normal diver body temperature, below the high ambient temperature. Some specialty companies use also a set of refrigeration pumps, simultaneously for several divers.

\section{The Equipment in Use}

\subsection{Personal Alarm Dosimeter (PAD)}

Anyone entering the reactor area will wear the PAD. It records the total amount of radiation that the divers receive and is located on a portion of the diving body (leg, chest, arm or head), as in (Figure no. 1).

If one of the component parts fails, it is most likely that the diver's life is in danger until the problem is resolved.

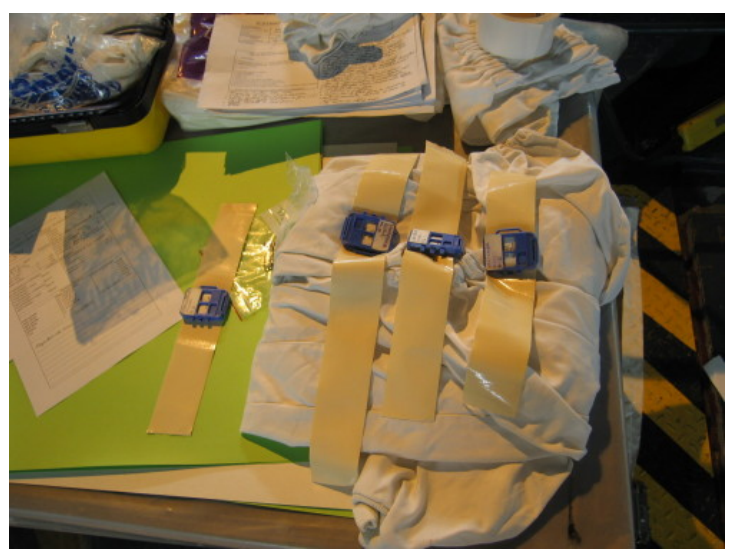

Figure no. 1: Personal Alarm Dosimeter

(Blog: Histoires d'un scaphandrier or the Stories of a Commercial Diver, 2015)

\subsection{Diving Suit}

When there is necessary to be equipped, the diver will be dressed in a tight, cool suit, with all the parts of the dosimeter assembly attached. 
The suit (Figure no. 2), is made of vulcanized rubber that prevents contamination, very easy to clean and waterproof. The cooled suit has a valve inside the dry suit and outside the suit there is a similar valve, attached to the water cooling hose. The helmet is fitted to the suit by means of a rigid collar, provided with a waterproof sealing gasket.

\subsection{Diving Helmet}

The diving helmet is specially designed for radiation protection, as shown in (Figure no. 3).

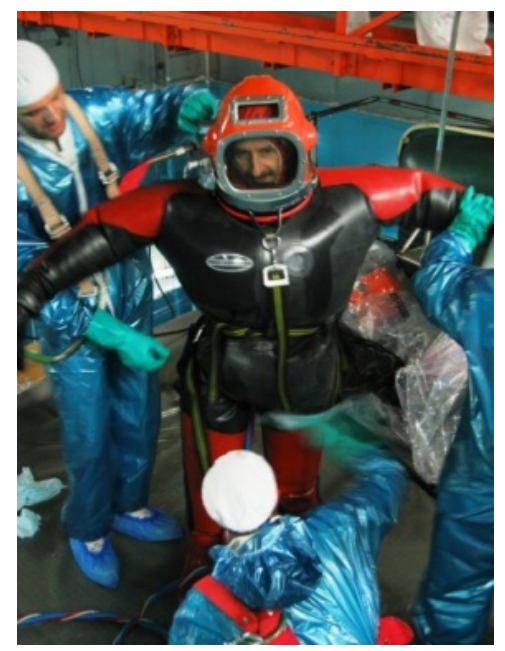

Figure no. 2: Diver equipped for diving in radioactive environment

(Blog: Histoires d'un scaphandrier or the Stories of a Commercial Diver, 2015)

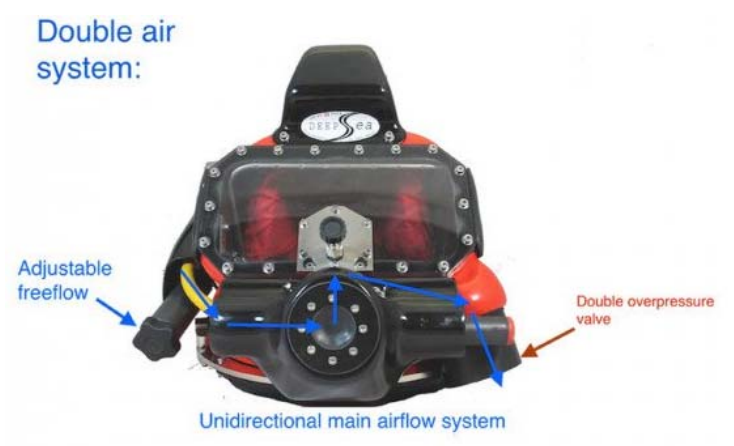

Figure no. 3: DeepSea diving helmet for radioactive environment

(Northern Diver Commercial, 2019)

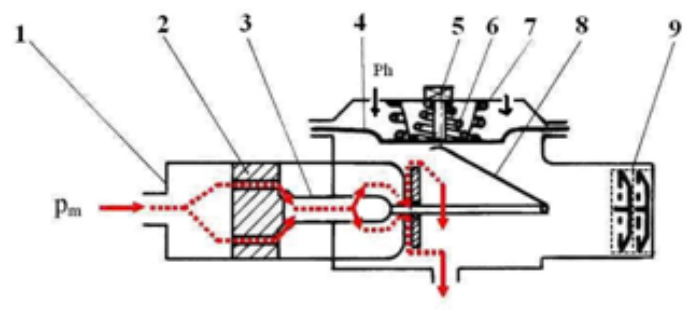

Ph+5mbar

Figure no. 4: Second stage with component overpressure of the Underwater Intervention Equipment in contaminated water

(Stanciu, 2010)

1 Housing 2 Seat 3 Downstream valve 4 Membrane 5 Adjusting screw 6. Return arc 7

Pressure spring 8 Lever 9 Valve block

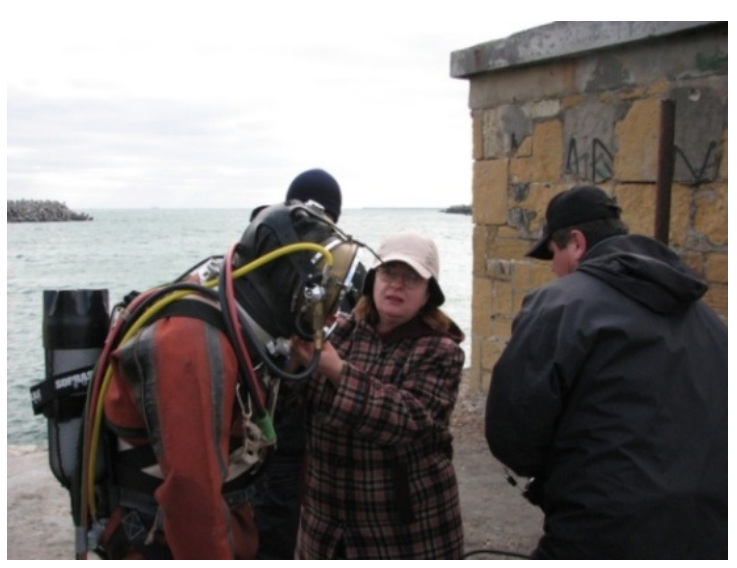

Figure no. 5: Testing the experimental model of the Underwater Equipment of interventions in contaminated water

(Stanciu, 2010)

The second stage is supplied with a slight pressure and is provided with 2 exhaust valves block, so as to avoid the accidental penetration of the contaminated water. Such a pressure reductor was designed and manufactured at the Diving Center, it is represented in (Figure no. 4) and it equips the experimental model of the Underwater equipment for interventions in contaminated water from (Figure no. 5). The evolution of the pressures by the mechanism of the second pressure reducer is highlighted in (Figure no. 6). 


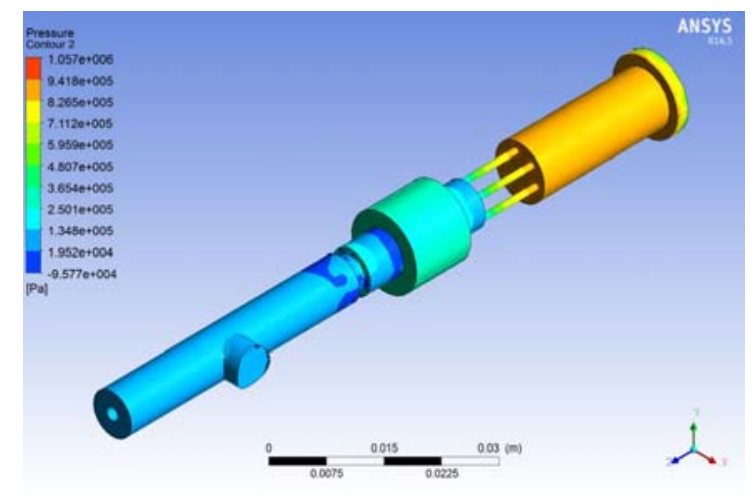

Figure no. 6

(Stanciu, 2017)

For the support of the divers activities, it was written by the specialists of the Diving Center, in 2011, a "Diving Guide in Contaminated waters", that also includes a chapter dedicated to the activity of divers in radioactive environment (Stanciu, 2011).

\section{Diving Procedure}

The diving team is at the station and does the latest checks to make sure everything is ready for the dive. All attention is directed to the diver, to track its entry into the water. The descent is made with the transport platform, under the supervision of the radiation protection team, to ensure that everything is in order and that the dosimeter is not accidentally hited (Figure no. 7).

From the moment the equipment is ready, the diver descends into the water on a platform and moves quickly, but safely, to the work point.

During the diver is in the water, the dosimeter is lowered to check the radiation dose of the various objects, to know if they can be used or sent to the surface for decontamination.

If the mini dosimeter (PAD) attached to the diving suit indicates that the diver is safe, he may proceed his work.

Once he has fully accomplished the tasks entrusted to him, he will proceed to clean the work area. Only after the tools and equipment have been completely cleaned, the diver is brought to the surface. After everything has been taken out of the water, the cord and the diver must be washed. More attention should be paid to rinsing the diver's hands and feet who comes in direct contact with contaminated water materials. After the diver is clean, the decontamination team and surface support personnel come into action. The surface staff brushes the diving suit very quickly, to remove any splash of water. The diver is tired, is carefully unzipped by the other team members and is fully checked by the decontamination team, after being placed on the floor (Figure no. 8).

Controlled in order: the cooling system of the suit and the mini dosimeter, after which they are removed, the diver is decontaminated and can be dressed. If it is found not to be clean, the diver is sent to the shower for cleaning and monitorised until any trace of radiation disappears. Only then the dive ends in radioactive medium.

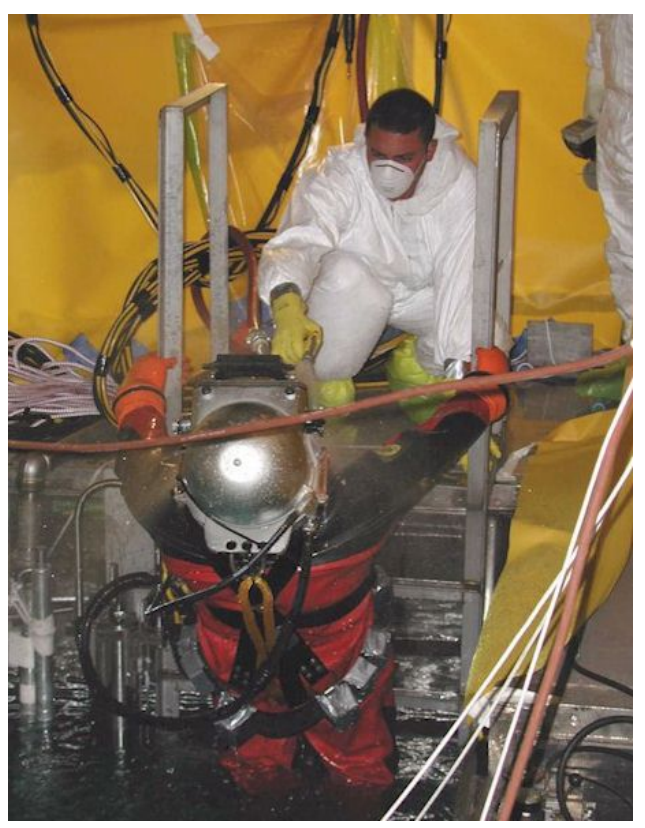

Figure no. 7: Diver supervised by the protection team

(Sheaffer, 2015) 


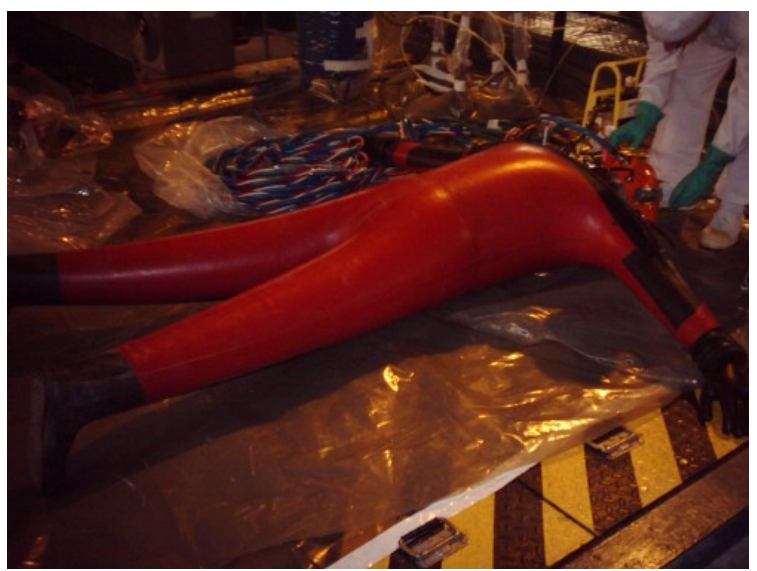

Figure no. 8: Decontamination of the diver after immersion in radioactive environment

(Blog: Histoires d'un scaphandrier or the Stories of a Commercial Diver, 2015)

\section{Results \\ 5. Practical Applications of Research}

The nuclear energy industry initially developed as a potential source of cheaper energy than fossil fuels (coal, natural gas, etc.). One of the chains used to obtain electricity based on the nuclear fission of uranium is the CANDU - CANadian Deuterium Uranium, such as Cernavoda Nuclear Power Plant. The economical advantage of a CNE (Nuclear Power Plant) over a fossil fuel plant is the reduced fuel costs (natural uranium).

In a nuclear power plant, the reactor has the same function as a boiler on coal, gas or oil in a conventional power plant producing the heat that turns water into the steam, which then rotates the turbine. The nuclear reactor is a controlled system, that produces heat by the fission (division) of the uranium cores.

The reactor is shaped like a horizontal cylinder, called a calandria vessel, made of thin stainless steel sheet (thickness 20-30 mm), because it withstands low pressures. It is in the Reactor Building. In this area, the pressure is lower than the atmospheric pressure, so that, in the event of leakage of radioactive material, they do not reach the atmosphere. Due to this pressure difference, the entry and the exit into the Reactor Building are made through the equipment lock and, respectively, the personnel lock.

The characteristic components of a reactor are:

- Nuclear fuel;

- Moderator;

- The cooling agent (CNE Cernavodă, 2010).

In a CNE, the most dangerous accident that can happen is the loss of the cooling agent with uranium damage. In order to avoid such an event, a CANDU type $\mathrm{CNE}$ is provided by design with several physical barriers that prevent the release of radioactive material into the environment.

The exposure to radiation leads to the absorption of a fraction of their energy ("absorbed dose"). The variation of the radiation dose over a period of time (minute, hour) represents the dose flow and is usually expressed in $\mathrm{mSv} / \mathrm{h}$. The legal dose limits for the whole body are: $20 \mathrm{mSv} /$ year for professionally exposed workers and $1 \mathrm{mSv} /$ year for the population.

The administrative dose limit for the whole body applicable to Cernavodă NPP is $18 \mathrm{mSv} /$ year for occupational exposure.

Table no. 1

Radioactive substances

\begin{tabular}{|c|l|}
\hline $\boldsymbol{N r}$. & Radioactive substance \\
\hline $\mathbf{1}$ & Radioactive iodine \\
\hline $\mathbf{2}$ & Tritium \\
\hline $\mathbf{3}$ & Noble gases \\
\hline $\mathbf{4}$ & Gamma Radiation \\
\hline $\mathbf{5}$ & Beta Radiation \\
\hline
\end{tabular}

The threats at Cernavodă NPP are generated by the presence of the substances in (Table no. 1) (CNE Cernavodă, 2010).

The gamma and beta radiation collected are measured with the dosimetric cassettes (Thermo Luminiscent Dosimeter TLDs). Personal alarm dosimeter (PAD Personal Alarm Dosimeter) allows you to set alarm thresholds for gamma dose, 
gamma dose flow and working time. If in one area there are one or more radiological hazards, for which the total flow rate exceeds $10 \mathrm{~Sv} / \mathrm{h}$, they are noted on specific warning panels: "Radiation danger". The highest penetration power between alpha, beta and gamma radiation is gamma radiation. For this reason the external danger associated with them is strictly monitored and controlled.

The heavy water (D2O) that exists in the CANDU reactors becomes the tritiated heavy water after passing through the active zone. Tritiated heavy water vapor reaches the body through inhalation and absorption through the skin. The dose received from tritium is calculated by analyzing urine samples.

At Cernavoda NPP, the turbine is composed of a high pressure body and three low pressure bodies. The amount of water consumed for cooling the various technological processes in the engine room of the turbine (mainly for cooling the condenser) is very large and consequently the nuclear power plants are located near large water sources.

The water taken from a natural source is raw water. The entire quantity of raw water used at Cernavoda NPP is taken from the Danube - Black Sea channel and is subjected to a filtration treatment carried out in the House of Sieges. Circulating water (condenser cooling water) holds the major share of the total cooling water flow consumed by the boiler. It is used for cooling the steam capacitors of the turbine.

The Diving Center has specialists capable of collaborating with those of Cernavodă NPP, they are contracting staff, with clear tasks for a limited period of time. In this regard, they followed a course for obtaining the "Certificate of attestation of the training for the contracting personnel with access to the Radiological Zone".

The intervention of our specialists consists of the technical assistance they provide to the Cernavodă CNE workers during the 3 to 3 year review. The checks of the leaks of the reactor are made at an overpressure of $1.24 \mathrm{bar}$, in the area of the personnel lock. The team from the Diving Center is present with a treatment barocamera, ready to intervene with the specific procedures, in case of an accident of work when working under pressure.

\section{Conclusions}

Over the years, the representatives of nuclear companies and those of diving companies, working together, have formed a cooperation partnership through which they have jointly developed solutions to most of the practical problems that have arisen. Instead of draining the entire contaminated basin, which would be very costly and lead to massive irradiation of workers, it is preferable to use divers. They are usually the first callers in case of an emergency intervention. They work in tanks with fuel leaks, make settlements for better fuel storage, have to enter the fuel transfer channels, replace sensors and repair cracks in fuel transfer trolleys, also do numerous repairs to reactors (equipment, debit pads), recovers lost items that would cause fuel damage, etc. All these works are not done under the pressure of the elapsed time, even if the plant's stationary results in very large material losses.

Table no. 2

The efects of nuclear radiations on the human body

\begin{tabular}{|c|l|}
\hline Radiation value $(\mathrm{Sv})$ & \multicolumn{1}{|c|}{ Radiation effects } \\
\hline $0-0.25$ & Lack of any apparent disorder \\
\hline $0.25-0.5$ & Blood changes occur, injected eyes \\
\hline $0.5-1$ & $\begin{array}{l}\text { Fatigue, dizziness, cataracts, blood changes, opacity of the lens, } \\
\text { appearance of moles }\end{array}$ \\
\hline
\end{tabular}




\begin{tabular}{|c|l|}
\hline Radiation value $(\mathrm{Sv})$ & \multicolumn{1}{|c|}{ Radiation effects } \\
\hline $1-2 \mathrm{~Sv}$ & $\begin{array}{l}\text { Dizziness, fatigue, reducing the number of red blood cells, decreasing } \\
\text { the resistance to infections }\end{array}$ \\
\hline $2-4$ & $\begin{array}{l}\text { The same disorders as above accompanied by several deaths between } \\
2-6 \text { weeks after irradiation }\end{array}$ \\
\hline $4-6$ & $50 \%$ deaths within 30 days from irradiation \\
\hline$>6$ & $100 \%$ deaths, less than 15 days after irradiation \\
\hline
\end{tabular}

Contamination can be fixed or free depending on the possibility of removal of radioactive material deposited on surfaces. Free contamination can be removed by deletion, while fixed contamination cannot be removed by simple methods. Fixed contamination is a danger of external irradiation, while free contamination represents a danger of both external and internal irradiation. Free contamination is more dangerous because it can be spread or enter the body through ingestion and/or inhalation. This is the reason why in the radiologically contaminated areas the consumption of food, drinks and smoking is not allowed, except for specially arranged places. The effects of radiation on the human body are devastating, (Table no. 2) shows some of them (CNE Cernavodă, 2010).

In conclusion, the diver must aim not to be exposed to an irradiation of more than $20 \mathrm{mSv} / \mathrm{year}$ (2,000 mrem/year), this being the limit admitted by international bodies and most companies for the human body. Exceptionally, for certain divers, they are allowed exposure at $50 \mathrm{mSv} /$ year (5,000 $\mathrm{mrem} /$ year $)$. When they reach their maximum absorption value, they are never allowed to work in a nuclear power plant.

\section{REFERENCES}

Blog: Histoires d'un scaphandrier or the Stories of a Commercial Diver. (2015). The funny story of 3 nuclear commercial divers, available at: http://papyone.overblog.com/article-the-funny-story-of-3-nuclear-commercial-divers-125559003.html, accessed on 12 December 2019. $U A-007$.

CNE Cernavodă. (2010). Instructaj introductiv general pentru personalul contractor,

Naval Sea Systems Command USA. (2008). Guidance for Diving in Contaminated Waters. Revision 1, available at: www.navsea.navy.mil/Contaminated-Water-Diving, accessed on 11 December 2019.

Northern Diver Commercial. (2019). Deep Sea Nucelar Dive Helmet, available at: www.ndiver-commercial.com/nuclear-dive-helmet, accessed on 12 December 2019.

Sheaffer, W. L. (2015). The Life of a Nuclear Diver, available at: www.diving heritage.com/nuclearkern.htm, accessed on 12 December 2019.

Stanciu, T. (2010). The Respiratory Circuit of the Diving Equipment for Interventions in Contaminated Waters. Ovidius University Annals Series: Civil Engineering, Vol. 1, Issue 12, 211-214.

Stanciu, T. (2011). Ghid de scufundare în ape contaminate. Planul sectorial de cercetare - dezvoltare al M.Ap.N., 28-33.

Stanciu, T., Scupi, A., \& Dinu, D. (2017). Solving the problems of gas flow external resistence throught the breathing apparatus of divers using Computational Fluid Dynamics. Researches Marines, no. 47, 257. 